Raijmakers, N.J.H., Heide, A. van der, Kouwenhoven, P.S.C., Thiel, G.J.M.W. van, Delden, J.J.M. van, Rietjens, J.A.C. Assistance in dying for older people without a serious medical condition who have a wish to die: a national cross-sectional survey. Journal of Medical Ethics: 2015, 41(2), 145-150

\begin{tabular}{|l|l|}
\hline $\begin{array}{l}\text { Postprint } \\
\text { Version }\end{array}$ & 1.0 \\
\hline Journal website & $\underline{\text { http://jme.bmj.com/content/early/2013/11/29/medethics-2012-101304.long }}$ \\
\hline Pubmed link & $\underline{\text { http://www.ncbi.nlm.nih.gov/pubmed/24335917 }}$ \\
\hline DOI & $10.1136 /$ medethics-2012-101304 \\
\hline
\end{tabular}

This is a NIVEL certified Post Print, more info at http://www.nivel.eu

\title{
Assistance in dying for older people without a serious medical condition who have a wish to die: a national cross-sectional survey
}

\author{
NATASJA J H RAIJMAKERS ${ }^{1,2}$, AgNES VAN DER HEIDE ${ }^{1}$, PAULine S C KOUWENHOVEN ${ }^{3}$, \\ GHISLAINE J M W VAN THIEL ${ }^{3}$, JOHANNES J M VAN DELDEN ${ }^{3}$, JUDITH A C RIETJENS ${ }^{1}$ \\ ${ }^{1}$ Department of Public Health, Erasmus MC, University Medical Center Rotterdam, \\ Rotterdam, The Netherlands \\ 2'Department of Medical Oncology, Erasmus MC, University Medical Center Rotterdam, \\ Rotterdam, The Netherlands \\ ${ }^{3}$ Julius Center for Health Sciences, University Medical Center Utrecht, Utrecht, The \\ Netherlands
}

Correspondence to Dr Natasja J H Raijmakers, Department of Public Health, Erasmus MC, University Medical Center Rotterdam, PO Box 2040, Rotterdam 3000 CA, The Netherlands; n.raijmakers@erasmusmc.nl

\begin{abstract}
Background The Dutch euthanasia law regulates physician assistance in dying for patients who are suffering unbearably from a medical condition. We studied the attitudes of the Dutch population to assistance in dying for older persons who have a wish to die without the presence of a serious medical condition.
\end{abstract}

Methods A cross-sectional survey was conducted among a random sample of the Dutch public (response rate $78 \%, \mathrm{n}=1960$ ), using statements and vignettes about attitudes to assistance in dying for older persons who are tired of living.

Results A minority of $26 \%$ agreed with a vignette in which a physician warrants the request for physician-assisted suicide of an older person who is tired of living without having a serious medical condition. Furthermore, 21\% agreed with the statement 'In my opinion euthanasia should be allowed for persons who are tired of living without having a serious disease'. People supporting euthanasia for older persons who are tired of living were more likely than opponents to be highly educated (OR 1.6; 95\% CI 1.1 to 2.3), to be nonreligious (OR 1.7; 95\% CI 1.3 to 2.3), to have little trust in physicians (OR 1.6; 95\% CI 1.2 to 2.2), and to prefer to make their own healthcare decisions (OR 1.7; 95\% CI 1.3 to 2.3 ).

Conclusions Although it is lower than the level of support for assistance in dying for patients whose suffering is rooted in a serious medical condition, our 
Raijmakers, N.J.H., Heide, A. van der, Kouwenhoven, P.S.C., Thiel, G.J.M.W. van, Delden, J.J.M. van, Rietjens, J.A.C. Assistance in dying for older people without a serious medical condition who have a wish to die: a national cross-sectional survey. Journal of Medical Ethics: 2015, 41(2), 145-150

finding that a substantial minority of the general public supports physician assistance in dying for older people who are tired of living implies that this topic may need to be taken seriously in the debate about end-of-life decision-making.

\section{BACKGROUND}

Populations around the world are ageing, and high-quality medical care for older people has become more important than ever. However, excellent care cannot always prevent the problem for some older people that aging coincides with such a reduced sense of purpose in life that they develop a wish to die. Previous studies report this to be the case in 5-25\% of older persons.1-7 Often such wishes are associated with having physical and mental health problems, such as progressive diseases and increasing disability. However, sometimes older people have this wish without having a serious medical condition. Such wishes have been found to be associated with, for example, loneliness, a small social network, a perceived lack of control, and living in residential care.1 $1,4,4,0$ Older persons without a serious medical condition who wish to die are often referred to as being 'tired of living'.9 One of the worries about older persons 'being tired of living' is that they opt for assistance in dying because they are tired of being a burden to society. Older people are often portrayed as non-contributors to society10; therefore society should protect these vulnerable groups from such pressure. It is important to study trends in end-oflife decision-making to see if such a mechanism is present. A recent systematic literature review showed that euthanasia and physician-assisted suicide (PAS) are less common in persons older than 80 years of age.11

Studies on people with a death wish have shown that having a wish to die does not necessarily mean they want to pursue this wish. A distinction has been made between passive and active ideators. Passive ideators report a wish to die but do not pursue their wish, while active ideators seriously consider taking their own life. The estimated prevalence of active ideators among older persons is 1-9\%.3, 6,7 Furthermore, it is known that suicide attempts at an older age have a higher case fatality than attempts at a younger age.12

In the Netherlands, the Euthanasia Act since 2002 regulates the practice of assistance in dying, both euthanasia and PAS, and formulates criteria of due care. Physicians must perform assistance in dying according to these criteria, otherwise their actions can be illegal. Two main criteria of due care require the physician to assess whether there is a voluntary and well-considered request from the patient and whether the patient is suffering unbearably without prospect of improvement. Assistance in dying for persons who are tired of living without having a serious medical condition is not subject to this legislation and is therefore criminalised. However, there is currently a lively debate in Dutch society about whether it could be justified to regulate euthanasia and PAS for older persons who are tired of living, since a group of prominent older citizens is seeking societal, medical and legal support for the allowance of euthanasia and PAS in such instances. This debate stems from the medicalised euthanasia practice in the Netherlands, with little room for strictly autonomy-based preferences. This claim echoes earlier debates, starting in the early nineties when Professor Drion suggested that older persons should be allowed to use a suicide pill when they are tired of living. In 2002, the Supreme Court stated that unbearable suffering, resulting in a request for PAS, should arise from a medical 
Raijmakers, N.J.H., Heide, A. van der, Kouwenhoven, P.S.C., Thiel, G.J.M.W. van, Delden, J.J.M. van, Rietjens, J.A.C. Assistance in dying for older people without a serious medical condition who have a wish to die: a national cross-sectional survey. Journal of Medical Ethics: 2015, 41(2), 145-150

cause in order to be subject to the Dutch Act. The reasoning was that, in non-medical suffering, physicians are not able to judge the extent of suffering and whether or not other options are available. More recently, the Royal Dutch Medical Association followed this reasoning by stating that they consider the presence of a medical condition to be a strict prerequisite for euthanasia and PAS.

International studies have shown that the proportion of the general public that supports assistance in dying varies between one-third and two-thirds13-16 and that these proportions seem to be increasing in Europe.17 Although this increase seems to have stabilised in the Netherlands, it is still among the top accepting countries of euthanasia in Europe.18

However, there is limited insight into the level of public support for assistance in dying for older people who are tired of living. Recent polls show that almost 26-70\% of the Dutch general public think that older people who are tired of living, without having a terminal/serious disease, should be able to receive assistance in dying.19-21 More insight into public opinions strengthens the societal debate about euthanasia by informing about the level of societal support for the current legislation. Furthermore, it informs healthcare professionals, who can be confronted with these opinions when caring for patients. Therefore the aim of this study was to gain insight into the attitudes of the Dutch general public regarding assistance in dying for older persons who wish to die but have no serious medical condition, and to describe the characteristics of supporters and opponents.

\section{METHODS}

\section{Study design and population}

This national cross-sectional survey was conducted in the Netherlands. An online questionnaire was administered to a random sample of households, using an established panel (CentERdata, University of Tilburg, The Netherlands). This panel comprised a random sample of all households in the Netherlands, based on the national addresses database. Households at these addresses were contacted by phone or mail to obtain informed consent for participation in the panel. All members of the contacted households were invited to participate in the panel. CentERdata hosts this panel and the panel remains representative by replacing drop-outs with comparable households with the following characteristics: household income, household composition, region, and level of urbanisation.22 During the survey period, 2503 persons were included in the panel. Multiple measures were in place to avoid selection bias of this digital panel, such as guaranteeing accessibility for all selected households by providing them with a free tool that enabled response by internet or television. If needed, additional devices were provided.

\section{Questionnaire}

The structured questionnaire was developed within the KOPPEL Study,23 a national study on knowledge and opinions of the general public and professionals on end-oflife care and decisions. Part of this questionnaire assessed attitudes to euthanasia and PAS for older persons without a serious medical condition. The questionnaire included statements, vignettes and closed questions. The respondents were asked to indicate to what extent they agreed with four statements on their attitude to 
Raijmakers, N.J.H., Heide, A. van der, Kouwenhoven, P.S.C., Thiel, G.J.M.W. van, Delden, J.J.M. van, Rietjens, J.A.C. Assistance in dying for older people without a serious medical condition who have a wish to die: a national cross-sectional survey. Journal of Medical Ethics: 2015, 41(2), 145-150

euthanasia, using a five-point Likert scale. Further, respondents' attitudes to the acceptability of PAS were assessed using two vignettes (box 1) - that is, hypothetical case descriptions representing an older person who is tired of living and asking for PAS versus a reference case of a patient with incurable cancer who asks for PAS. Respondents were asked whether they thought that the person described in the vignette suffered unbearably, whether they agreed with the physician's action, and whether they would request PAS if they imagined themselves in this situation. Answer categories were: 'yes', 'no' and 'I don't know'. In addition, respondents were asked whether they trusted physicians to comply with their wishes about medical care and treatment at the end of life. Preferences for end-of-life decision-making styles were measured by providing three options: 'physicians should make decisions based on what is best for me', 'physicians and I should make decisions together' and 'I should make decisions based on what is best for me'. The questionnaire was developed by the KOPPEL research group, comprising physicians, ethicists, researchers and a methodologist. Questions were partly based on previous research24 ,25 and partly on expert opinion of the research group members.

\section{[Box 1]}

A pilot study was conducted to examine the length, comprehensibility and feasibility for online use among 14 members of the Dutch general public. They varied in educational level, age and gender. This pilot resulted in small adjustments of the questionnaire. The digital questionnaire was sent to all households of the panel as a separate questionnaire. All members of the household were able to respond by using their unique personal log-in.

Two reminders were sent between December 2009 and February 2010.

Sociodemographic data for the panel were obtained through CentERdata (age, gender, education level, composition of the household, religious beliefs, urbanisation of living area, and health status) based on self-reported data. For comparison, background characteristics of the adult Dutch population were obtained from Statistics Netherlands (CBS).26

\section{Statistical analysis}

Summary data are presented as frequencies and proportions for categorical variables. Univariate analyses followed by multivariate binary logistic regression analyses were used to calculate ORs with 95\% CIs for the relationships between positive attitudes to assistance in dying in cases of being tired of living and personal characteristics independently. We used all predictors in the multivariate model without selection. Three different dependent variables were used: 'agreeing with the vignette describing PAS in the case of a person who is tired of living'; 'having a positive attitude to euthanasia for people who are tired of living, without having a serious disease'; 'in favour of drugs for the very old people that enable them, if they want to, to end their life'. The attitudes to euthanasia and drugs for the oldest old were scored on a fivepoint Likert scale and dichotomised ('totally agree' and 'agree' were recoded as 'having a positive attitude' and 'neutral'; 'disagree' and 'totally disagree' were recoded as 'having a non-positive attitude'). Attitudes to PAS as described in the vignette were scored as ‘yes', 'no' and 'I don't know', and 'yes' was coded as 
Raijmakers, N.J.H., Heide, A. van der, Kouwenhoven, P.S.C., Thiel, G.J.M.W. van, Delden, J.J.M. van, Rietjens, J.A.C. Assistance in dying for older people without a serious medical condition who have a wish to die: a national cross-sectional survey. Journal of Medical Ethics: 2015, 41(2), 145-150

'having a positive attitude, and 'no' and 'I don't know' were recoded as 'having no positive attitude'.

The personal characteristics, education, religious belief, health status, trusting a physician to comply with wishes, and the importance of making one's own health decisions, were also dichotomised. Age was imputed as continuous into the model. All statistical analyses were carried out using SPSS for Windows software, V.17.0.

\section{Ethics considerations}

The Dutch Medical Research Involving Human Subjects Act (also known by its Dutch abbreviation WMO) does not apply to this study. Therefore, no formal ethics approval from the medical ethics committee was needed. All data were collected anonymously, and the researchers were in possession of no personal data to ensure confidentiality.

\section{RESULTS}

\section{Sample characteristics}

In total, 2004 of 2503 questionnaires were returned, and 1960 were complete and eligible for analysis (response 78\%). The reasons for exclusion of 44 questionnaires were incompleteness $(n=17)$ and age of the respondent $<18(n=27)$. The respondents were aged between 18 and 95 years. Compared with the Dutch general public, respondents in the sample were statistically significantly more often older, male, highly educated, living with a partner, and native Dutch (table 1).

\section{[TABLE 1]}

\section{Attitudes to assistance in dying}

Of the respondents, 21\% agreed and 52\% disagreed with the statement 'In my opinion euthanasia should be allowed for people who are tired of living without having a serious disease'. Furthermore, 36\% were in favour of enabling the oldest old to obtain medication to end their life if they want to (suicide pill), whereas 35\% were not in favour of such a pill. Somewhat over half of the respondents thought that everybody should have the right to euthanasia when they wish (57\%), and 53\% supported the right of everybody to determine their own life and death (table 2).

\section{[TABLE 2]}

Table 3 shows the opinions of the respondents regarding the vignettes describing PAS in two cases with different types of suffering (box 1). Respondents less often judged the suffering of an old person who is tired of living as unbearable (20\%) compared with the suffering of a patient with terminal cancer $(69 \%)(p<0.001)$. Respondents also less often agreed with the physician performing PAS in the case of a person being tired of living (26\%) than in the case of a patient with cancer (65\%) $(p<0.001)$. The results show that $19 \%$ would ask for euthanasia themselves if they were in the situation described in the vignette of an old person who was tired of living, versus $48 \%$ if they had cancer as described in the second vignette $(p<0.001)$. 
Raijmakers, N.J.H., Heide, A. van der, Kouwenhoven, P.S.C., Thiel, G.J.M.W. van, Delden, J.J.M. van, Rietjens, J.A.C. Assistance in dying for older people without a serious medical condition who have a wish to die: a national cross-sectional survey. Journal of Medical Ethics: 2015, 41(2), 145-150

Respondents who judged the suffering described in the vignettes as unbearable were more likely than others to agree with the physician performing PAS $(\mathrm{p}<0.001)$ and would be more likely to ask for euthanasia for themselves in a similar situation $(\mathrm{p}<0.001)$ (data not shown).

\section{[TABLE 3]}

\section{Characteristics of supporters and opponents}

Euthanasia for a person who is tired of living without having a serious medical condition was significantly more likely to be accepted by people with a higher education (OR 1.6; 95\% CI 1.1 to 2.3), with no religious belief (OR 1.7; 95\% CI 1.3 to 2.2), with little trust that the physician would comply with their wishes (OR 1.6; 95\% CI 1.2 to 2.2) and who considered it important to be able to make their own end-of-life decisions (OR 1.7; 95\% CI 1.3 to 2.4). The acceptance was not associated with respondents' age (OR 1.0; 95\% CI 0.99 to 1.0) or health status (OR 1.2; 95\% CI 0.8 to 1.7). Agreement with the vignette describing PAS in the case of a person who is tired of living was associated with the same personal characteristics, except for higher education (OR 0.9; 95\% CI 0.4 to 2.1).

Respondents who were in favour of enabling the oldest old to obtain medication to end their life if they wished were more likely to be higher educated (OR 1.6, 95\% CI 1.2 to 2.2) and not religious (OR 2.2 95\% CI 1.7 to 2.8) than those who opposed that option. They were also more likely to have little trust in the physician to comply with their wishes (OR 2.4; 95\% CI 1.8 to 3.3) and to consider it important to be able to make their own end-of-life decisions (OR 1.8; 95\% CI 1.4 to 2.3). Age and health status were not related to respondents' opinions (table 4).

\section{[TABLE 4]}

\section{DISCUSSION}

Our study shows that a substantial minority of the Dutch general public supports euthanasia and PAS for older people who have a wish to die because they are tired of living without having a serious medical condition. Furthermore, one-third of the general public supports the idea of enabling the oldest old to obtain pills to end their life if they wish. Overall, support for assistance in dying for older people who have a wish to die seems less than support for euthanasia in general and PAS for patients who are terminally ill.

Our findings are in line with a recently published study among older people in the Netherlands investigating their attitudes to euthanasia. This study showed that onethird of older people agree with making a suicide pill available for older people who have a wish to die because they are tired of living in the absence of a severe disease.27 Furthermore, our study shows less support for assistance in dying for older people who are tired of living than polls of right-to-die organisations.20 This difference in support might be explained by the selection of respondents: a random sample of the general public versus recruitment of respondents via the websites of these organisations. 
Raijmakers, N.J.H., Heide, A. van der, Kouwenhoven, P.S.C., Thiel, G.J.M.W. van, Delden, J.J.M. van, Rietjens, J.A.C. Assistance in dying for older people without a serious medical condition who have a wish to die: a national cross-sectional survey. Journal of Medical Ethics: 2015, 41(2), 145-150

Our study also shows that age and health are not associated with acceptance of assistance in dying for older people who are tired of living. The phenomenon of response shift might explain this. Response shift involves the process of changing internal standards and values and the reconceptualisation of quality of life in the face of a new situation, such as deteriorating health.28 In other words, people tend to adjust to their situation and adjust their quality of life rating. In line with this, our findings suggest that experiencing declining health as well as old age does not instigate favouring or opposing assistance in dying for persons who are tired of living.

Furthermore, those in favour of assistance in dying for older people were more likely to be higher educated, have less trust in their physician to comply with their wishes, and more often prefer to make their own health decisions rather than allowing physicians to make them. A shared theme seems to be that those who support assistance in dying value control. This idea goes together with literature about suicide among older people that illustrates that a feeling of loss of control plays an important role in suicide among older people, especially in those who had been predominantly 'action-oriented' people all their lives.29,30 Furthermore, a recent interview study aiming to understand why older people want to die also showed that the need for control is an important issue.31 Moreover, in the Netherlands, the public debate in the media on assistance in dying for older persons who are tired of living is set off by arguments related to the need to maintain control.32 A recent media study has shown that one of the most common arguments against euthanasia is that society should protect the vulnerable,32 and the elderly are such a vulnerable group. This consideration may play a role in public support for euthanasia and PAS for older people who are tired of living.

Little is known about the true prevalence of older people who wish to die because they are tired of living. It has been estimated that Dutch physicians annually receive 400 requests for assistance in dying from older people because they are tired of living.31 Thus, the medical practice of euthanasia and PAS for older people who are tired of living appears to be relatively small, given our aging society with 2.5 million individuals aged 65 or older, and 19\% of the general public indicating that they would ask for PAS if they were tired of living.

Some methodological considerations should be taken into account with respect to this study. First, despite a good response rate, the respondents were not fully representative of the Dutch population; the respondents were slightly older, more often male, better educated and more often sharing a household. These differences were significant $(\mathrm{p}<0.05)$. Older people are possibly more inclined to participate in a survey about end-of-life issues. Furthermore, migrants were under-represented, which is often the case in general surveys. To reach migrants, different approaches should be considered, such as stratified sampling. This may have led to an overestimation of the support for assistance in dying for older people who are tired of living. Second, an internet panel for surveys may involve some degree of selection bias. To minimise such selection bias, the CentERdata panel was used, which enables all selected members to participate (no restriction to internet users only) and consists of a randomised sample of people (not self-selected). Despite being a random sample, some selection bias remains because the sampling was based on registered addresses. Therefore, institutional households were not included, such as people living in nursing homes. Third, another limitation to a quantitative survey is that 
Raijmakers, N.J.H., Heide, A. van der, Kouwenhoven, P.S.C., Thiel, G.J.M.W. van, Delden, J.J.M. van, Rietjens, J.A.C. Assistance in dying for older people without a serious medical condition who have a wish to die: a national cross-sectional survey. Journal of Medical Ethics: 2015, 41(2), 145-150

statements and vignettes, in order to be standardised, inevitably simplify the complex reality, stripping it of its emotional and personal context. To ensure the veracity and quality of the vignettes, the vignette on being tired of living was based on a true court case. However, this has led to some additional differences in variables between the two vignettes that might also bring about differences in the responses of the respondents. Furthermore, our study shows less support for the statement about assistance in dying in the case of being tired of living than for the vignette addressing the same topic. Whether these results reflect the use of different measures (vignette vs statement) or the use of different ways of assisting to die (euthanasia vs PAS) is unclear.

In conclusion, a substantial minority of the Dutch public considers euthanasia and PAS acceptable for older people who have a wish to die because they are tired of living. Hence it appears that, within a medicalised euthanasia practice, there is also support for meeting autonomy-based wishes to die.

Persons who support assistance in dying for older people who are tired of living are not necessarily the same persons that are the subject of this debate. This suggests that society needs to protect the vulnerable from public opinions such as these. This study provides empirical evidence that can help policy makers in developing end-of-life regulations. Although it is lower than the level of support for assistance in dying for patients whose suffering is rooted in a serious medical condition, our finding that a substantial minority of the general public supports physician assistance in dying for older people who are tired of living implies that this topic should be taken seriously in the debate about end-of-life care and decision-making.

\section{FOOTNOTES}

- Contributors All authors contributed to the conception and design of the study. NJHR, JACR and AvdH were responsible for the data acquisition and analysis. All authors were consulted for the interpretation of data. NJHR and JACR drafted the article, and the other authors revised it critically. All authors gave final approval of the version to be published.

- Funding The Netherlands Organisation for Health Research and Development, ZonMw.

- Competing interests None.

- Provenance and peer review Not commissioned; externally peer reviewed.

\section{REFERENCES}

Rurup ML, Deeg DJ, Poppelaars JL, et al . Wishes to die in older people: a quantitative study of prevalence and associated factors. Crisis 2011;32(4):194-203.

Barnow S, Linden M . Epidemiology and psychiatric morbidity of suicidal ideation among the elderly. Crisis 2000;21(4):171-80.

Forsell Y, Jorm AF, Winblad B . Suicidal thoughts and associated factors in an elderly population. Acta Psychiatr Scand 1997;95(2):108-11.

Jorm AF, Henderson AS, Scott R, et al. Factors associated with the wish to die in elderly people. Age Ageing 1995;24(5):389-92.

Rao R, Dening T, Brayne C, et al. Suicidal thinking in community residents over eighty. Int J Geriatr Psychiatry 1997;12(3):337-43. 
Raijmakers, N.J.H., Heide, A. van der, Kouwenhoven, P.S.C., Thiel, G.J.M.W. van, Delden, J.J.M. van, Rietjens, J.A.C. Assistance in dying for older people without a serious medical condition who have a wish to die: a national cross-sectional survey. Journal of Medical Ethics: 2015, 41(2), 145-150

Scocco P, De Leo D. One-year prevalence of death thoughts, suicide ideation and behaviours in an elderly population. Int J Geriatr Psychiatry 2002;17(9):842-6.

Scocco P, Fantoni G, Rapattoni M, et al. Death ideas, suicidal thoughts, and plans among nursing home residents. J Geriatr Psychiatry Neurol 2009;22(2):141-8.

Dennis M, Baillon S, Brugha T, et al. The spectrum of suicidal ideation in Great Britain: comparisons across a 16-74 years age range. Psychol Med 2007;37(6):795-805.

Rurup ML, Pasman HR, Goedhart J, et al. Understanding why older people develop a wish to die: a qualitative interview study. Crisis 2011;32(4):204-16.

Martin R, Williams C, O'Neill D. Retrospective analysis of attitudes to ageing in the Economist: apocalyptic demography for opinion formers. BMJ 2009;339:b4914.

Rietjens JA, Deschepper R, Pasman R, et al. Medical end-of-life decisions: does its use differ in vulnerable patient groups? A systematic review and meta-analysis. Soc Sci Med 2012;74(8):1282-7.

Jansen E, Buster MC, Zuur AL, et al. Fatality of suicide attempts in Amsterdam 1996-2005. Crisis 2009;30(4):180-5.

Cohen J, Marcoux I, Bilsen J, et al. European public acceptance of euthanasia: sociodemographic and cultural factors associated with the acceptance of euthanasia in 33 European countries. Soc Sci Med 2006;63(3):743-56.

Schuklenk U, van Delden JJ, Downie J, et al. End-of-life decision-making in Canada: the report by the Royal Society of Canada expert panel on end-of-life decision-making. Bioethics 2011;25(Suppl 1):1-73.

Singer PA, Choudhry S, Armstrong J, et al. Public opinion regarding end-of-life decisions: influence of prognosis, practice and process. Soc Sci Med 1995;41(11):1517-21.

Emanuel EJ. Euthanasia and physician-assisted suicide: a review of the empirical data from the United States. Arch Intern Med 2002;162(2):142-52.

Cohen J, Marcoux I,Bilsen J, et al. Trends in acceptance of euthanasia among the general public in 12 European countries (1981-1999). Eur J Public Health 2006;16(6):663-9.

Cohen J, Van Landeghem P, Carpentier N, et al. Public acceptance of euthanasia in Europe: a survey study in 47 countries. Int J Public Health. Published Online First: 5 Apr 2013. doi:10.1007/s00038-013-0461-6

Broadcasting Organisation Max. Max Omroep Poll: I don't want to live anymore. http://www.omroepmax.nl/?waxtrapp=jjviqKsHnHUVOJYAmywWpzwW (accessed 13 Dec 2012).

Peters MHA. Tired of Living. What do we talk about? [Voltooid leven. Waar praten we over?]. NVVE. Amsterdam: NVVE, 2011.

Eenvandaag. http://www.zorgvisie.nl/Kwaliteit/Nieuws/2013/8/Meerderheid-voor-euthanasiebij-levensmoe-1326554W/ (accessed 17 Aug 2013).

CentERdata. CenterPanel: University of Tilburg, http://www.centerdata.nl/nl/wat-doenwe/dataverzameling/centerpanel (accessed 30 Jun 2013).

Kouwenhoven PS, Raijmakers NJ, van Delden JJ,et al. Opinions of health care professionals and the public after eight years of euthanasia legislation in the Netherlands: a mixed methods approach. Palliat Med 2013;27(3):273-80.

Rietjens JA, van der Heide A, Onwuteaka-Philipsen BD, et al. Preferences of the Dutch general public for a good death and associations with attitudes towards end-of-life decision-making. Palliat Med 2006;20(7):685-92.

KlijnA, et al Holsteyn J, Trappenburg M. The Quest for Limits. Law and Public Opinion on Euthanasia in the Netherlands. In: KlijnA, et al. eds. Regulating Physician-Negatiated Death. 's-Gravenhage: Elsevier, 2001:109-27.

CBS. Statistics Netherlands (CBS) Statline, 2009.

Buiting HM, Deeg DJ, Knol DL, et al. Older peoples' attitudes towards euthanasia and an end-of-life pill in The Netherlands: 2001-2009. J Med Ethics 2012;38(5):267-73.

Stiggelbout AM, de Vogel-Voogt E. Health state utilities: a framework for studying the gap between the imagined and the real. Value Health 2008;11(1):76-87.

Kjolseth I, Ekeberg O, Steihaug S. 'Why do they become vulnerable when faced with the challenges of old age?' Elderly people who committed suicide, described by those who knew them. Int Psychogeriatr 2009;21(5):903-12. 
Raijmakers, N.J.H., Heide, A. van der, Kouwenhoven, P.S.C., Thiel, G.J.M.W. van, Delden, J.J.M. van, Rietjens, J.A.C. Assistance in dying for older people without a serious medical condition who have a wish to die: a national cross-sectional survey. Journal of Medical Ethics: 2015, 41(2), 145-150

Kjolseth I, Ekeberg O, Steihaug S. Why suicide? Elderly people who committed suicide and their experience of life in the period before their death. Int Psychogeriatr 2010;22(2):209_ 18.

Rurup ML, Muller MT, Onwuteaka-Philipsen BD, et al. Requests for euthanasia or physicianassisted suicide from older persons who do not have a severe disease: an interview study. Psychol Med 2005;35(5):665-71.

Rietjens JA, Raijmakers NJ, Kouwenhoven PS, et al. News media coverage of euthanasia: a content analysis of Dutch national newspapers. BMC Med Ethics 2013;14:11.

\section{BOX AND TABLES}

\section{Box 1 Vignettes of persons requesting physician-assisted suicide: different types of suffering}

\section{Old age and tired of living ${ }^{*}$}

Mr de Bruyn is 86 years old. He used to be a professor at the university. He enjoyed his life at that time. He never got married and has no children. Now he has grown old, and many of his friends have died. He often feels lonely. He is in good physical and mental condition. Mr de Bruyn is aware that he could live for many years, and he fears that. He would rather be dead and has told his family doctor this several times. Mr de Bruyn repeatedly asks his general practitioner for physician-assisted suicide. The general practitioner decides to honour his request and performs physician-assisted suicide.

II Reference case: cancer, with loss of control and severe pain Mrs de Jong (60 years old) has breast cancer with metastases. Despite undergoing several treatments, her disease is no longer curable. She is in severe pain which cannot be adequately relieved. In addition, she dislikes the feeling of loss of control that she experiences. In her working days, she always felt in control. She indicates that she cannot take it anymore. She asks her general practitioner for physician-assisted suicide. The general practitioner decides to honour her request and performs physician-assisted suicide.

*Not in accordance with the Dutch Euthanasia Act. 
Table 1 Background characteristics of the respondents to the online survey, compared with the Dutch population

\begin{tabular}{|c|c|c|c|}
\hline Characteristic & $\begin{array}{l}\text { Respondents } \\
(n=1960)\end{array}$ & $\begin{array}{l}\text { Initial } \\
\text { sample }\end{array}$ & $\begin{array}{l}\text { Dutch } \\
\text { population* }\end{array}$ \\
\hline Age (years) & $53.4 \pm 15.1$ & 49.9 & 48 \\
\hline \multicolumn{4}{|l|}{ Gender } \\
\hline Male & 54 (52 to 56$)$ & 52 & 50 \\
\hline Female & 46 (44 to 48$)$ & 48 & 50 \\
\hline \multicolumn{4}{|l|}{ Educationt } \\
\hline Low & 32 (30 to 34$)$ & 32 & 32 \\
\hline Middle & 29 (27 to 31$)$ & 31 & 40 \\
\hline High & 39 (37 to 41$)$ & 37 & 29 \\
\hline \multicolumn{4}{|l|}{ Composition household } \\
\hline Living with partner & 76 (74 to 78$)$ & 79 & 64 \\
\hline Living without partner & 22 (20 to 24$)$ & 18 & 36 \\
\hline \multicolumn{4}{|l|}{ Religious beliefs } \\
\hline Yes & 58 (56 to 60$)$ & 58 & 59 \\
\hline No & 42 (40 to 44$)$ & 42 & 41 \\
\hline \multicolumn{4}{|l|}{ Urbanisation living area } \\
\hline Low/middle & 61 (59 to 63$)$ & 60 & 57 \\
\hline High & 39 (37 to 41$)$ & 40 & 43 \\
\hline
\end{tabular}

Values are $\%(95 \% \mathrm{Cl})$ or $\%$, except those for age which are mean $\pm \mathrm{SD}$ or mean.

*Data based on statistics from 2009 from Statistics Netherlands (CBS); http://statline. cbs.nl/statweb.

tLow, level 1-3 according to International Standard Classification of Education (ISCED) guidance (primary school, lower secondary general education, lower vocational education); middle, level 4 according to ISCED guidance (intermediate vocational or higher secondary general education); high, level 5-7 according to ISCED guidance (higher vocational education or university). 
Raijmakers, N.J.H., Heide, A. van der, Kouwenhoven, P.S.C., Thiel, G.J.M.W. van, Delden, J.J.M. van, Rietjens, J.A.C. Assistance in dying for older people without a serious medical condition who have a wish to die: a national cross-sectional survey. Journal of Medical Ethics: 2015, 41(2), 145-150

Table 2 Opinions of the respondents regarding assistance in dying in different circumstances

\begin{tabular}{|c|c|c|c|}
\hline In my opinion... & $\begin{array}{l}\% \\
\text { agree }\end{array}$ & $\begin{array}{l}\% \\
\text { neutral }\end{array}$ & $\begin{array}{l}\% \\
\text { disagree }\end{array}$ \\
\hline $\begin{array}{l}\text {... everybody should have a right to } \\
\text { euthanasia }\end{array}$ & 57 & 20 & 23 \\
\hline $\begin{array}{l}\text {... euthanasia should be allowed for people } \\
\text { who are tired of living, without having a } \\
\text { serious disease }\end{array}$ & 21 & 27 & 52 \\
\hline $\begin{array}{l}\text {... every human being has the right to } \\
\text { determine their own life and death }\end{array}$ & 53 & 25 & 23 \\
\hline $\begin{array}{l}\ldots \text { the oldest old should be able to get } \\
\text { medications that enable them, if they wish, } \\
\text { to end their life }\end{array}$ & 36 & 30 & 35 \\
\hline
\end{tabular}

Agree, sum of agree and totally agree. Disagree, sum of disagree and totally disagree.

Table 3 Opinions on physician-assisted suicide in different cases of suffering

\begin{tabular}{lll}
$\begin{array}{l}\text { Vignette I } \\
\text { Old age and tired of } \\
\text { living (\%) }\end{array}$ & $\begin{array}{l}\text { Vignette II } \\
\text { Cancer: loss of control } \\
\text { with severe pain (\%) }\end{array} \quad$ p Value \\
\hline
\end{tabular}

In your opinion, does this situation concern unbearable suffering?

$\begin{array}{llll}\text { Yes } & 20 & 69 & <0.001 \\ \text { No } & 65 & 13 & \\ \text { Don't } & 15 & 18 & \\ \text { know } & & & \\ \text { Do you personally agree with the physician's action? } & \\ \text { Yes } & 26 & 65 & <0.001 \\ \text { No } & 58 & 15 & \\ \text { - Don't } & 16 & 19 & <0.001 \\ \text { know } & & \\ \text { Imagine yourself as the person in this situation. Would you ask your physician for } \\ \text { euthanasia? } & & \\ \text { Yes } & 19 & 48 \\ \text { - No } & 53 & 16 & \\ \text { - Don't } & 28 & 36 & \\ \text { know } & & \end{array}$


Raijmakers, N.J.H., Heide, A. van der, Kouwenhoven, P.S.C., Thiel, G.J.M.W. van, Delden, J.J.M. van, Rietjens, J.A.C. Assistance in dying for older people without a serious medical condition who have a wish to die: a national cross-sectional survey. Journal of Medical Ethics: 2015, 41(2), 145-150

Table 4 Factors associated with attitudes to assistance in dying

\begin{tabular}{|c|c|c|c|}
\hline Factor & $\begin{array}{l}\text { Positive attitude to statement 'Euthanasia } \\
\text { should be allowed for people who are tired } \\
\text { of living, without having a serious disease.'* } \\
\text { OR ( } 95 \% \mathrm{Cl})\end{array}$ & $\begin{array}{l}\text { Personally agreeing } \\
\text { with PAS as described } \\
\text { in vignettet } \\
\mathrm{OR}(95 \% \mathrm{Cl})\end{array}$ & $\begin{array}{l}\text { Positive attitude to statement 'The oldest } \\
\text { old should be able to obtain drugs that } \\
\text { enable them, if they wish, to end their } \\
\text { life.' } \\
\text { OR }(95 \% \mathrm{Cl})\end{array}$ \\
\hline \multicolumn{4}{|l|}{ Demographic characteristics } \\
\hline Age (per year) & 1.00 (0.99 to 1.01$)$ & $1.02(1.00$ to 1.05$) \ddagger$ & 1.00 (0.99 to 1.01$)$ \\
\hline Male (vs female) & 0.92 (0.69 to 1.24$)$ & 0.59 (0.30 to 1.13$)$ & 0.84 (0.65 to 1.09$)$ \\
\hline $\begin{array}{l}\text { Having no religious beliefs (vs having } \\
\text { religious beliefs) }\end{array}$ & 1.67 (1.25 to 2.23$)$ & 2.04 (1.05 to 3.96$)$ & 2.20 (1.70 to 2.84$)$ \\
\hline $\begin{array}{l}\text { Living with partner (vs living without } \\
\text { partner) }\end{array}$ & 0.77 (0.55 to 1.08$)$ & $0.98(0.45$ to 2.14$)$ & 0.89 (0.66 to 1.20$)$ \\
\hline \multicolumn{4}{|l|}{ Health } \\
\hline $\begin{array}{l}\text { Good self-perceived health status (vs } \\
\text { not having good self-perceived health) }\end{array}$ & 1.23 (0.83 to 1.82$)$ & $0.88(0.34$ to 2.25$)$ & 1.31 (0.92 to 1.86$)$ \\
\hline $\begin{array}{l}\text { Preference for making one's own } \\
\text { end-of-life decisions (vs no preference } \\
\text { for making one's own end-of-life } \\
\text { decisions) }\end{array}$ & 1.74 (1.28 to 2.36$)$ & $1.69(0.86$ to 3.31$)$ & 1.84 (1.40 to 2.32$)$ \\
\hline \multicolumn{4}{|c|}{$\begin{array}{l}\text { Adjusted ORs were estimated by multivariate logistic regression analysis; method=Enter. (ie, each independent variable was entered at the same time). } \\
\text { Bold indicates statistically significant ORs. } \\
\text { "These analyses included } 1.187 \text { respondents with complete information on all variables. Positive attitude has been defined as agreeing (agree and totally agree) with statement. } \\
\text { †These analyses included } 194 \text { respondents with complete information on all variables. } \\
\text { †Because of rounding, } 1.00 \text { is included in Cl, but this OR is not statistically significant. } \\
\text { PAS, physician-assisted suicide. }\end{array}$} \\
\hline
\end{tabular}

